\title{
Careful Echocardiographic Analysis of Right Ventricular Function as a Long-Term Prognostic Variable in Systolic Heart Failure
}

\author{
Pavan Atluri, MD
}

$\mathbf{O}$ ver the past decade, the importance of right ventricular (RV) function on the long-term survival of a patient suffering from systolic heart failure has been increasingly recognized. Much of this knowledge has been gained from the advancements in mechanical circulatory support and our realization that a functional RV is tantamount to long-term survival following isolated left ventricular assist device (LVAD) implantation. Numerous studies have illustrated diminished survival post-LVAD placement in the presence of poor RV function. ${ }^{1,2}$ Moreover, risk stratification has routinely placed patients with poor RV function among the highest risk for failure and death post-LVAD, which has prompted most heart failure surgeons and cardiologists alike to accept early RVAD intervention with concerns of RV failure. $^{3}$ As opposed to the neonatal population that can often be converted from a biventricular to a single-ventricle circulation with passive, gradient dependent flow through the pulmonary circulation, it is clear that in adult patients a functioning, active $\mathrm{RV}$ is requisite for stable hemodynamic function, due in large part to the development of pulmonary vascular resistance with age.

\section{Article p 2176}

On a broader sense, investigators are continuing to search for predictors of poor outcome in the presence of systolic heart failure. Namely, those risk factors that can be modified. The majority of clinical heart failure research has focused on indices of left heart dysfunction and secondary manifestations (ie, age, renal function, pulmonary disease, hepatic dysfunction, sodium, weight, blood pressure, heart rate, and B-type natriuretic peptide). ${ }^{4,5}$ A recent study by Kinugasa et al, published in the Journal, devised a simple mortality risk score using these variables based upon multivariate analysis. ${ }^{6}$ But only lately has the importance of sustainable RV function been recognized as a valuable variable in predicting longterm survival. The secondary analysis of the BEST trial has demonstrated a statistically significant decrease in survival in the presence of RV failure. ${ }^{7}$ Similarly, tricuspid regurgitation, a surrogate measure of RV failure, has been demonstrated to correlate with poor long-term outcomes independent of systolic function. ${ }^{8,9}$ The severity of each of tricuspid regurgitation, pulmonary hypertension, and RV dysfunction has been demonstrated to be an independent prognostic factor. ${ }^{10}$

Although the significance of the RV in maintaining hemodynamic function has begun to be recognized, we have not mastered the ability to adequately assess RV dysfunction. Hemodynamic monitoring via right heart catheterization is largely pre- and afterload sensitive and manifests variability between patients; most critically, it is invasive. Magnetic resonance imaging is very sensitive, but remains a very expensive study. Investigators have studied numerous echocardiographic parameters to evaluate RV function. One major echocardiographic variable, tricuspid annular plane systolic excursion (TAPSE), has demonstrated excellent correlation with RV function, ${ }^{11,12}$ but the prognostic significance of the peak velocity of the tricuspid annulus has not previously been illustrated.

In this issue of the Journal, Dr Chrysohoou and colleagues have very nicely demonstrated a strong correlation between echocardiographically determined pulse-wave TDI readings of peak systolic velocity of the lateral tricuspid annulus and adverse events (either death or hospitalizations). ${ }^{13}$ In their study, the authors prospectively studied 180 consecutive patients with systolic heart failure and all of them underwent echocardiography. A $13.9 \%$ mortality rate was seen in the study population. Analysis demonstrated a statistically significant inverse relationship between adverse events and peak systolic velocity of the tricuspid annulus. Additionally, the authors found an inverse correlation between creatinine clearance and adverse events. The authors should be commended for their study. It provides evidence to clinically quantify tricuspid annular motion as a prognostic variable while managing patients with systolic heart failure.

Studies such as that of Chrysohoou et al enhance our understanding of the RV and the role of the right heart in hemodynamic failure. Our knowledge of the right heart remains immature and needs to be further expanded. Future studies focused on enhancing our understanding of right heart dysfunction, quantification of right heart physiology, and the prognostic implications of RV failure are required.

The opinions expressed in this article are not necessarily those of the editors or of the Japanese Circulation Society.

Received July 13, 2011; accepted July 14, 2011; released online August 2, 2011

Division of Cardiovascular Surgery, Department of Surgery, Perelman School of Medicine, University of Pennsylvania, Philadelphia, PA, USA

Mailing address: Pavan Atluri, MD, Assistant Professor of Surgery, Division of Cardiovascular Surgery, Department of Surgery, Perelman School of Medicine, University of Pennsylvania, 3400 Spruce Street, 6 Silverstein Pavilion, Philadelphia 19130, PA, USA. E-mail: pavan.atluri@uphs.upenn.edu

ISSN-1346-9843 doi:10.1253/circj.CJ-11-0748

All rights are reserved to the Japanese Circulation Society. For permissions, please e-mail: cj@j-circ.or.jp 


\section{References}

1. Lietz K, Long JW, Kfoury AG, Slaughter MS, Silver MA, Milano $\mathrm{CA}$, et al. Outcomes of left ventricular assist device implantation as destination therapy in the post-REMATCH era: Implications for patient selection. Circulation 2007; 116: 497-505.

2. Matthews JC, Koelling TM, Pagani FD, Aaronson KD. The right ventricular failure risk score a pre-operative tool for assessing the risk of right ventricular failure in left ventricular assist device candidates. J Am Coll Cardiol 2008; 51: 2163-2172.

3. Fitzpatrick JR 3rd, Frederick JR, Hiesinger W, Hsu VM, McCormick RC, Kozin ED, et al. Early planned institution of biventricular mechanical circulatory support results in improved outcomes compared with delayed conversion of a left ventricular assist device to a biventricular assist device. J Thorac Cardiovasc Surg 2009; 137: 971-977.

4. Abraham WT, Fonarow GC, Albert NM, Stough WG, Gheorghiade $\mathrm{M}$, Greenberg BH, et al. Predictors of in-hospital mortality in patients hospitalized for heart failure: Insights from the Organized Program to Initiate Lifesaving Treatment in Hospitalized Patients with Heart Failure (OPTIMIZE-HF). J Am Coll Cardiol 2008; 52: 347-356.

5. Lee DS, Gona P, Vasan RS, Larson MG, Benjamin EJ, Wang TJ, et al. Relation of disease pathogenesis and risk factors to heart failure with preserved or reduced ejection fraction: Insights from the Framingham heart study of the national heart, lung, and blood institute. Circulation 2009; 119: 3070-3077.

6. Kinugasa Y, Kato M, Sugihara S, Hirai M, Kotani K, Ishida K, et al.
A simple risk score to predict in-hospital death of elderly patients with acute decompensated heart failure: Hypoalbuminemia as an additional prognostic factor. Circ J 2009; 73: 2276-2281.

7. Meyer P, Desai RV, Mujib M, Feller MA, Adamopoulos C, Banach $\mathrm{M}$, et al. Right ventricular ejection fraction $<20 \%$ is an independent predictor of mortality but not of hospitalization in older systolic heart failure patients. Int J Cardiol 2011 [E-pub ahead of print].

8. Kjaergaard J, Akkan D, Iversen KK, Køber L, Torp-Pedersen C, Hassager C. Right ventricular dysfunction as an independent predictor of short- and long-term mortality in patients with heart failure. Eur J Heart Fail 2007; 9: 610-616.

9. Nath J, Foster E, Heidenreich PA. Impact of tricuspid regurgitation on long-term survival. J Am Coll Cardiol 2004; 43: 405-409.

10. Lee JW, Song JM, Park JP, Lee JW, Kang DH, Song JK. Longterm prognosis of isolated significant tricuspid regurgitation. Circ J 2010; 74: 375-380.

11. Kjaergaard J, Iversen KK, Akkan D, Møller JE, Køber LV, TorpPedersen $\mathrm{C}$, et al. Predictors of right ventricular function as measured by tricuspid annular plane systolic excursion in heart failure. Cardiovasc Ultrasound 2009; 7: 51.

12. Meluzin J, Spinarová L, Hude P, Krejcí J, Kincl V, Panovský R, et al. Prognostic importance of various echocardiographic right ventricular functional parameters in patients with symptomatic heart failure. J Am Soc Echocardiogr 2005; 18: 435-444.

13. Chrysohoou C, Antoniou CK, Kotrogiannis I, Metallinos G, Aggelis A, Andreou I, et al. Role of right ventricular systolic function on long-term outcome in patients with newly diagnosed systolic heart failure. Circ J 2011; 75: 2176-2181. 